\title{
Severe Cardiovascular Complications of COVID-19: a Challenge for the Physician
}

Nathalie Cristina Crivelari, ${ }^{1}$ Gisele Queiroz de Oliveira, ${ }^{2}$ Clarice Hyesuk Lee Park, ${ }^{2}$ Gregorio da Cruz Riemma, ${ }^{1}$ Isabela Bispo Santos da Silva Costa, ${ }^{1,2,3}$ Marcus Vinícius Guimarães de Lacerda, ${ }^{4,5}$ Glaucia Maria Moraes de

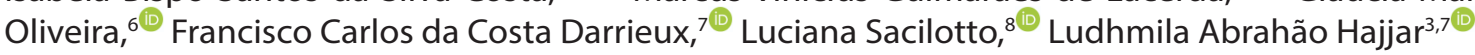

Hospital Paulistano, ${ }^{1}$ São Paulo, SP-Brazil.

Hospital Sírio-Libanês, ${ }^{2}$ São Paulo, SP-Brazil.

Instituto do Câncer do Estado de São Paulo - Hospital das Clínicas da Faculdade de Medicina da USP (HCFMUSP), ${ }^{3}$ São Paulo, SP - Brazil.

Fundação de Medicina Tropical Doutor Heitor Vieira Dourado, ${ }^{4}$ Manaus, AM - Brazil.

Fundação Oswaldo Cruz, Manaus, ${ }^{5}$ AM - Brazil.

Universidade Federal do Rio de Janeiro (UFRJ), ${ }^{6}$ Rio de Janeiro, $R J$ - Brazil.

Universidade de São Paulo - Instituto do Coração, ${ }^{7}$ São Paulo, SP - Brazil.

Universidade de São Paulo - Unidade de Arritmia, ${ }^{8}$ São Paulo, SP - Brazil.

\section{Introduction}

Since December 31, 2019, when China reported the appearance of cases of acute respiratory failure caused by a new species of coronavirus, SARS-CoV-2, which causes the disease called COVID-19, almost 20 million cases were confirmed, causing 726 thousand deaths worldwide. ${ }^{1}$ In Brazil, on August $8^{\text {th }}, 2020$, there was approximately 3 million cases and 100 thousand death by the disease. ${ }^{1}$

Its rapid spread, its high potential for hospitalization, and its high lethality, especially in the most fragile groups such as geriatric patients and those with comorbidities, particularly cardiovascular ones, make this pandemic a challenge never faced by modern medicine. To date, we have no specific medication that has effective and safe results for the treatment of COVID-19. The scientific community has sought to research drugs with therapeutic plausibility, and controlled and randomized studies are underway. Many therapeutic proposals are based on in vitro experiments. The medications used are described in case records, with no solid scientific evidence for their use, and with a

\section{Keywords}

COVID-19/complications; Pandemics; Betacoronavirus; Cardiovascular Diseases/complications; Arrhythmias, Cardiac; Stroke Volume; Death, Sudden; Chloroquine; Hydroxychloroquine; Azythromycin.

Mailing Address: Ludhmila Abrahão Hajjar

Universidade de São Paulo Instituto do Câncer do Estado de São Paulo Av. Dr. Arnaldo, 251. Postal Code: 01246-000, São Paulo, SP - Brazil.

E-mail: ludhmila@terra.com.br

DOI: https://doi.org/10.36660/ijcs.20200125 high probability of causing damage due to their adverse effects alone or in combination. ${ }^{2}$

In this context, multiple clinical and experimental studies with cell cultures mainly from China, suggested that chloroquine, a drug that has been used for more than 70 years in the treatment of malaria, and as an anti-inflammatory in autoimmune diseases such as systemic lupus erythematosus and rheumatoid arthritis, could play a role in the treatment of COVID-19. ${ }^{3}$ Currently, more than 80 studies using chloroquine and hydroxychloroquine alone or in combination with other drugs were registered worldwide, seeking to transpose the benefits described in cell cultures to human studies. ${ }^{2}$

Both chloroquine and its more recent analogue, hydroxychloroquine, have a direct effect on the replication of SARS-Cov-2 in experimental studies, reducing the efficiency of virus binding to ACE2 (angiotensin-2 converting enzyme) and increasing the lysosomal $\mathrm{pH}$, preventing the virus-cell fusion proces. ${ }^{4}$ One of the main problems to be faced in these studies is the complex pharmacokinetics of 4-aminoquinolines, which makes it difficult to extrapolate concentrations of culture media to doses in humans. ${ }^{5}$

Studies from China, with a questionable methodology, for not presenting a description of the results, study protocols, doses, side effects, and statistically significant benefits between the groups, made their use in the treatment of COVID-19 quite debatable. One of these

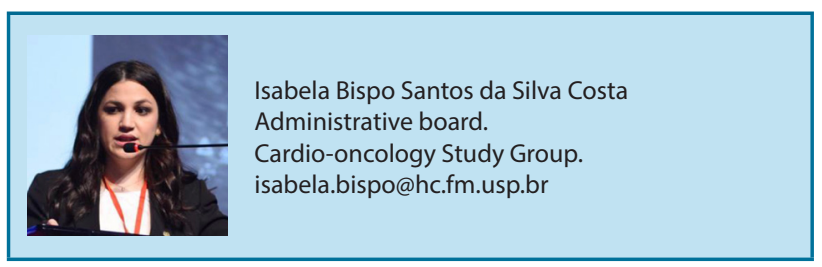

Manuscript received on May 15, 2020; reviewed on June 17, 2020; accepted on June 26, 2020. 
studies with a small number of patients showed that chloroquine was associated with a higher percentage of clinical and virologic cure and started to be adopted in that country in the treatment of COVID-19. ${ }^{6}$

Its use was approved by the United States Food and Drug Administration (FDA) with the blessings of President Donald Trump, ${ }^{7}$ although numerous side effects have been described such as fulminant liver failure, left ventricular failure, and arrhythmias (especially when prescribed in association to azithromycin). ${ }^{8}$

Azithromycin is a macrolide antibiotic widely used in clinical practice for upper and lower respiratory tract infections. It has also been studied for its in vitro effect against the Zika and Ebola viruses, and is often used to prevent serious respiratory tract infections when administered to patients suffering from viral infection. ${ }^{9-11}$ As a complementary therapy in the treatment of SARSCov-2, a small French study with 36 patients, with non-randomized controls from another cohort, reported that hydroxychloroquine with or without azithromycin reduced the detection of viral RNA in respiratory swabs, the most significant effect being associated with

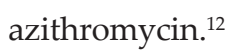

Currently, the FDA recommends the use of these medications "out of compassion", alone or in combination, until we have scientific evidence of their effectiveness. ${ }^{7}$ The Brazilian Ministry of Health, as of March 25, 2020, started to adopt chloroquine as an adjuvant therapy in the treatment of severe forms exclusively, without other support measures being neglected in its favor. ${ }^{13}$ Worldwide, this association has been used off-label in severe cases, outside of research protocols, but there is still no scientific evidence.

Although the safety profiles of chloroquine / hydroxychloroquine and azithromycin are suitable for isolated use in chronic diseases, both medications have the potential to prolong the QT interval, which greatly increases the risk of ventricular tachycardia (mainly Torsades de Pointes), bradycardia, and sudden death, especially in scenarios of systemic inflammation caused by epidemic respiratory viruses. ${ }^{14-16}$

It is observed that the highest incidence of events occurs in people with other predisposing factors, such as long QT syndrome, structural cardiovascular diseases, or the use of other drugs that prolong QT. ${ }^{17}$ In addition, it was demonstrated that approximately $20 \%$ of patients with COVID-19 have myocardial injury, 10\% have myocarditis, and 10 to $30 \%$ evolve with shock, ${ }^{18}$ which would multiply the probability of adverse effects in a proinflammatory and pro-thrombotic environment. These patients possibly have greater substrates for arrhythmia and electrolyte disturbances, and still in the critical phase of the disease, most patients admitted to intensive care units are treated with multiple combined therapies, such as vasoactive amines, diuretics, and serotonin 5-ht3 receptor antagonists, among others.

Both chloroquine / hydroxychloroquine and azithromycin have a known effect in prolonging the QT interval by blocking IKr (hERG) channels. ${ }^{19-20}$ Concomitant use was uncommon until the current pandemic. There are reports of prophylactic use in malaria and some sexually transmitted diseases and little data on increasing the QT interval with their combined use..$^{21}$ Furthermore, although drug-induced QT is a reliable indicator of high-risk Torsades de Pointes (TdP), this correlation is not linear. Some drugs increase the QT interval without increasing the risk of sudden death, while others increase the risk of TdP without necessarily extending the QT interval. ${ }^{22}$

Next, we describe 2 cases of patients admitted to the Intensive Care Unit with COVID-19, who used the association of hydroxychloroquine sulfate or chloroquine diphosphate with azithromycin, and presented with severe cardiovascular complications. The aim was to illustrate the observations described above, with emphasis of the lack of safety of combination therapies not tested in clinical trials capable of generating robust scientific evidence.

\section{Case 1}

A 70-year-old male patient sought the emergency room with a complaint of runny nose associated with dry cough for 5 days. One day ago he developed fever, mental confusion, lack of appetite and prostration. As a personal history, he reported arterial hypertension and epilepsy on carbamazepine. On physical examination, she was feverish, with an axillary temperature of $37.8^{\circ} \mathrm{C}$, heart rate of $110 \mathrm{bpm}$, blood pressure of $140 \times 80 \mathrm{~mm} \mathrm{Hg}$, respiratory rate of $25 \mathrm{irpm}$ and $83 \%$ saturation in room air. Lung auscultation revealed crackles on the left base.

Laboratory tests showed lymphopenia, increased C-reactive protein (CRP), lactate dehydrogenase (LDH), ferritin, and D-dimer. Other examinations and laboratory progress are shown in Table 1. The admission chest radiography showed a discrete bilateral infiltrate (Figure 1). The diagnostic hypothesis of sepsis of pulmonary focus with influenza syndrome was made, and the possibility of infection by SARS-CoV-2 was 
A - Admission to the ICU

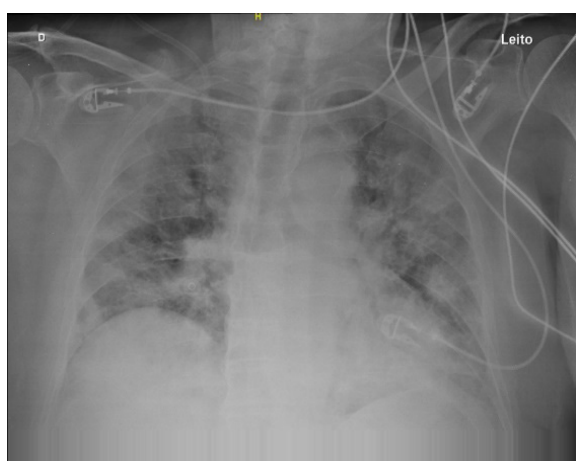

B - 1st day of hospitalization

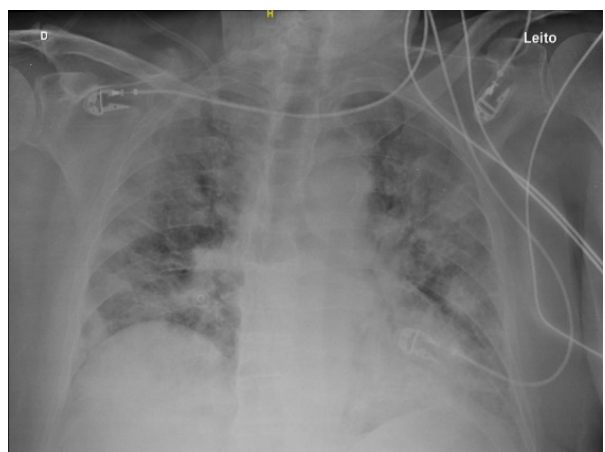

Figure 1 - Radiographic evolution of the patient Case 1. A - Admission to the ICU, B - 1st day of hospitalization. ICU: Intensive Care Unit.

raised. Antibiotic therapy with Piperacillin-Tazobactam, azithromycin, and oseltamivir was started, viral panel and PCR collected for COVID-19 (which proved to be positive in $24 \mathrm{~h}$ ) and the patient was referred to the ICU.

On the second day of admission to the ICU, the patient developed respiratory failure and decreased level of consciousness, being submitted to orotracheal intubation and initiation of invasive mechanical ventilation. The transthoracic echocardiogram showed no relevant changes, with preserved ejection fraction. Due to the clinical worsening, it was decided to start enteral hydroxychloroquine and to suspend other medications commonly associated with an increase in the QT interval, such as ondansetron, bromopride and haloperidol. The QTC interval was monitored from the first day of ICU admission with a daily electrocardiogram (ECG) as shown in Figure 2, which remained within the normal range until the sixth day of ICU. On the seventh day, the patient presented sinus bradycardia, enlargement of the QTc interval, and Q wave in D1 and in AVL, accompanied by hemodynamic worsening, with severe hypotension, hyperlactatemia, and metabolic acidosis. A new transthoracic echocardiogram was performed, which showed diffuse hypokinesia with a drop in ejection fraction to $30 \%$ and an increase in the levels of ultra-sensitive troponin I (1038ng / dL), with a reference value of up to $25 \mathrm{ng} / \mathrm{dL}$. Dobutamine was started in a progressively higher dose up to $15 \mathrm{mcg} / \mathrm{Kg}$ / min, with stabilization of the condition. There were no hydroelectrolytic disturbances. Hydroxychloroquine and azithromycin were suspended. On the ECG the following day, the QT interval had normalized, with no further QT prolongation after medication was discontinued. Repeated echocardiogram with partial recovery of the left ventricular ejection fraction to $45 \%$.

The patient evolved with multiple complications during hospitalization with acute renal failure requiring hemodialysis, epileptic seizures, and urinary tract infection, progressing to death on the 22nd day of hospitalization.

\section{Case 2}

Female patient, 92 years old, brought by her daughter to the emergency room with a history of dyspnea for 1 day, associated with generalized indisposition and weakness. She denied fever or flu-like symptoms. Daughter reported previous history of arterial hypertension, previous stroke with motor sequelae, lung cancer with radio surgery 6 years ago, and renal neoplasia with left nephrectomy 10 years ago, both without evidence of current disease.

Physical examination revealed dyspnea, with blood pressure 208x102 mm Hg, heart rate $134 \mathrm{bpm}$, respiratory rate $25 \mathrm{irpm}$, saturating $75 \%$ in room air, with cyanosis of the extremities. Lung auscultation demonstrated diffuse bilateral crackles. Oxygen support was started with a reservoir mask at $10 \mathrm{~L} /$ min with good clinical response, as well as infused nitroglycerin and administered furosemide.

On admission examinations, patient with leukocytosis and relative lymphopenia, high CRP, in addition to increased D-dimer, troponin, and BNP. Other 


\section{A - ECG at admission. HR 100bpm, QT 360ms QTc 423ms}

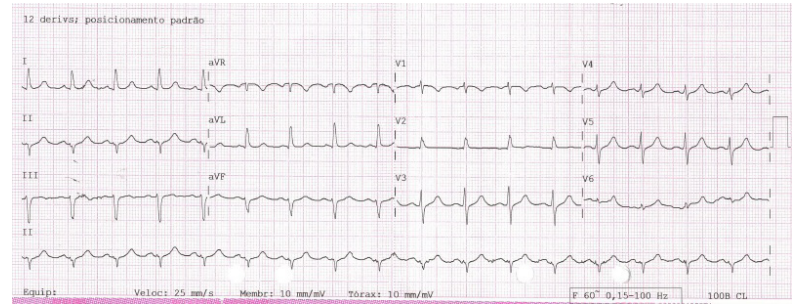

B - 2nd day in the ICU.

HR 75BPM QT 360ms QTc 391ms

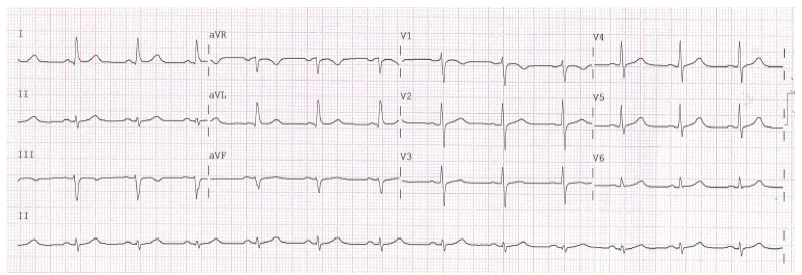

C -4 th day in the ICU. HR 83bpm,

QT 360ms, QTc $340 \mathrm{~ms}$

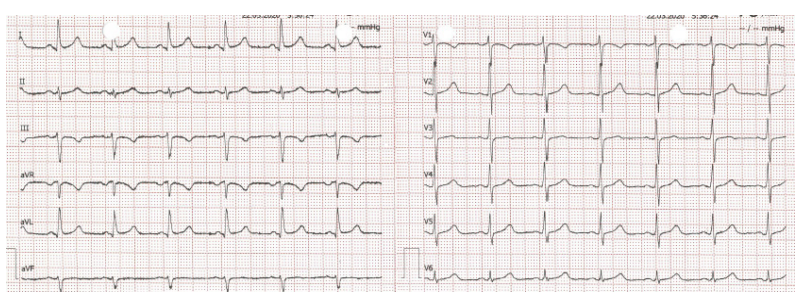

D - 6th day in the ICU. HR107bpm, QT 360ms, QTc 432ms

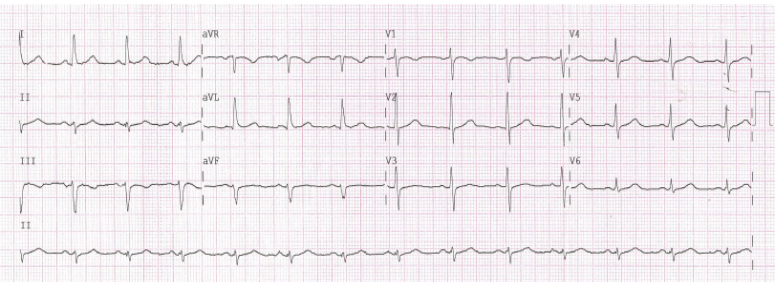

E - 7th day in the ICU. HR 60bpm,

QT 580ms, QTc 603ms

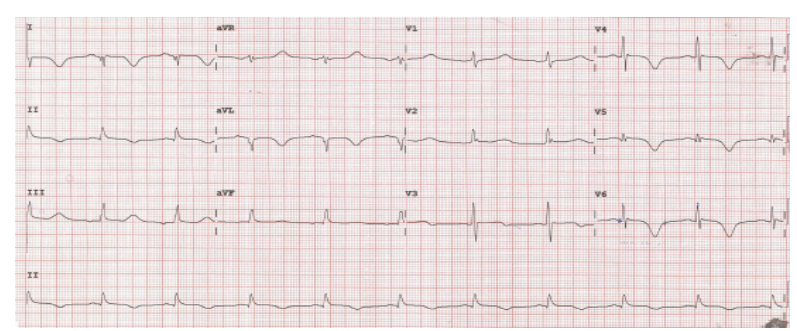

F - 8th day in the ICU. HR 100bpm, QT560ms, QTc 465ms

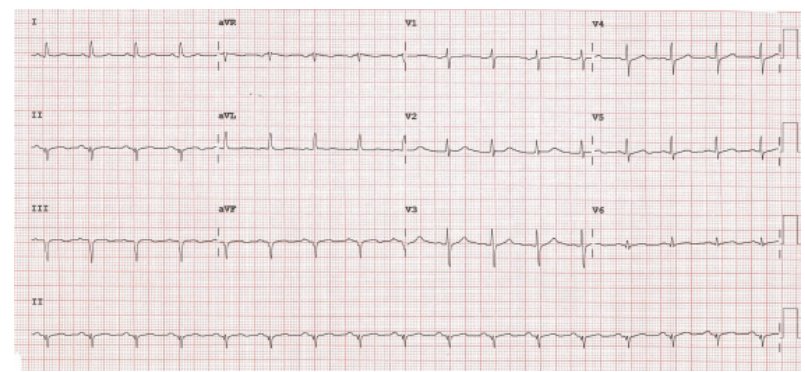

Figure 2 - Electrocardiographic evolution of the patient Case 1. A - Admission to the ICU, B - 2nd day in the ICU - day of prescription of chloroquine C - 4th day in the ICU, control of the onset of chloroquine; D - 6th day in the ICU; E - 7th day in the ICU - enlargement of the QTc interval $(\approx 600 \mathrm{~ms})$ and appearance of lateral inactive area, F - 8th day in the ICU - normalization of the interval. ECG: electrocardiogram; HR: heart rate; ICU: intensive care unit. 


\begin{tabular}{|c|c|c|c|c|c|c|c|c|c|c|}
\hline & Admission & D1 & D2 & D3 & D4 & D5 & D6 & D7 & D8 & D 10 \\
\hline $\begin{array}{l}\text { Hemoglobin } \\
\text { (g/dL) }\end{array}$ & 14.8 & 13.1 & 13.4 & 12.7 & 13.2 & 13.5 & 14 & 14.1 & 13.8 & 8.9 \\
\hline Hematocrit (\%) & 45.4 & 38.6 & 41.4 & 38.5 & 40.2 & 41.3 & 42.2 & 42.9 & 41.1 & 28.2 \\
\hline $\begin{array}{l}\text { Leukogram } \\
\left(\text { cells/mm } / \mathrm{mm}^{3}\right)\end{array}$ & 8050 & 9170 & 12610 & 8900 & 9730 & 14950 & 14010 & 17780 & 14080 & 37580 \\
\hline Band cells (\%) & $4 \%$ & $5 \%$ & $3 \%$ & $2 \%$ & $1 \%$ & $1 \%$ & 0 & $7 \%$ & $3 \%$ & $2 \%$ \\
\hline Neutrophils (\%) & $76 \%$ & $83 \%$ & $80 \%$ & $78 \%$ & $80 \%$ & $80 \%$ & $87 \%$ & $79 \%$ & $80 \%$ & $80 \%$ \\
\hline $\begin{array}{l}\text { Lymphocytes } \\
\left.\text { (cells } / \mathrm{mm}^{3}-\%\right)\end{array}$ & $805-10 \%$ & $642-7 \%$ & $\begin{array}{c}1261- \\
10 \%\end{array}$ & $\begin{array}{c}1602- \\
18 \%\end{array}$ & $681-7 \%$ & $1047-7 \%$ & $981-7 \%$ & $1067-6 \%$ & $1408-10 \%$ & $12 \%$ \\
\hline $\begin{array}{l}\text { Platelet } \\
(\text { cells/mm³) }\end{array}$ & 233.000 & 204.000 & 243.000 & 244.000 & 290.000 & 327.000 & 340.000 & 280.000 & 341.000 & 261.000 \\
\hline Urea (mg/dL) & 53 & 38 & & 37 & 53 & 67 & 107 & 63 & 61 & 131 \\
\hline $\begin{array}{l}\text { Creatinine } \\
(\mathrm{mg} / \mathrm{dL})\end{array}$ & 1.50 & 1.20 & 1.72 & 2.05 & 2.23 & 3.27 & 4.73 & 2.57 & 2.64 & 0.67 \\
\hline Sodium (mEq/L) & 135 & 136 & 141 & 139 & 139 & 141 & 140 & 139 & 130 & 135 \\
\hline $\begin{array}{l}\text { Potassium } \\
(\mathrm{mEq} / \mathrm{L})\end{array}$ & 3.7 & 3.3 & 3.6 & 3.4 & 2.9 & 3.2 & 3.4 & 4.8 & 4.5 & 5.5 \\
\hline $\begin{array}{l}\text { Ionic calcium } \\
(\mathrm{mmol} / \mathrm{L})\end{array}$ & 1.08 & 1.01 & 1.15 & 0.97 & 0.96 & 0.95 & 0.97 & 0.96 & 1.09 & 0.97 \\
\hline $\begin{array}{l}\text { Phosphorus } \\
\text { (mg/dL) }\end{array}$ & & 3.3 & 1.02 & & 4.5 & 4.2 & 3.6 & 4.5 & 2.5 & \\
\hline $\begin{array}{l}\text { Chlorine } \\
(\mathrm{mmol} / \mathrm{L})\end{array}$ & & 107 & & & 92 & 93 & 92 & 97 & 103 & 101 \\
\hline $\begin{array}{l}\text { Magnesium } \\
\text { (mg/dL) }\end{array}$ & & 2.0 & 1.8 & & 1.6 & 1.7 & 2.0 & 1.9 & 1.4 & 1.6 \\
\hline BNP (pg/mL) & & 18 & & 23 & 25 & 110 & 1120 & 1540 & 1000 & 154 \\
\hline $\begin{array}{l}\text { Troponin } \\
\text { (mg/dL) }\end{array}$ & & $>5$ & $>5$ & $>5$ & $>5$ & $>5$ & 1038 & 115 & 192 & 109 \\
\hline Ferritin (ng/mL) & & 631 & & & & 1137 & 1248 & 1755 & 1471 & 5095 \\
\hline D-dimer (ng/ml) & 928 & 1200 & 1470 & 2035 & 2561 & & 6064 & 5163 & 4813 & 8322 \\
\hline CRP (mg/dL) & 24.9 & 28.13 & 30.57 & 32.11 & 35.72 & 36.35 & 36.16 & 26.03 & 12.55 & 11.30 \\
\hline Lactate (mg/dL) & 18 & 18 & 14 & 23 & 22 & 32 & 41 & 35 & 24 & 20 \\
\hline LDH (UI/l) & & 448 & 576 & 499 & 526 & 533 & 539 & 439 & 237 & 543 \\
\hline $\begin{array}{l}\text { SWAB- } \\
\text { COVID-19 }\end{array}$ & Positive & & & & & & & & & \\
\hline
\end{tabular}

Clinical Data

\begin{tabular}{|c|c|c|c|c|c|c|c|c|c|c|}
\hline $\begin{array}{l}\text { Use of } \\
\text { vasopressors }\end{array}$ & & $x$ & $x$ & $x$ & $x$ & $x$ & $\mathrm{X}$ & $x$ & $x$ & \\
\hline Use of inotropic & & & & & & & & $x$ & $x$ & \\
\hline $\begin{array}{l}\text { Mechanical } \\
\text { ventilation }\end{array}$ & & $x$ & $x$ & $x$ & $x$ & $X$ & $\mathrm{X}$ & $x$ & $x$ & \\
\hline $\begin{array}{l}\text { LVEF } \\
\text { (echocardiogram) }\end{array}$ & $64 \%$ & & & & & & $30 \%$ & & $45 \%$ & \\
\hline Hemodialysis & & & & & & & $x$ & & & $x$ \\
\hline
\end{tabular}


examinations and laboratory evolution are available in Table 2. Imaging tests showed bilateral infiltrate with irregular and peripheral distribution pattern on chest radiography and echocardiogram with preserved ejection fraction $(61 \%)$, without segmental changes, with mild diastolic dysfunction (Figure 3).

Diagnostic hypotheses were made for acute hypertensive lung edema, associated with probable sepsis of pulmonary focus. Even without a typical clinical condition, due to the radiological pattern and the current pandemic context by COVID-19, it was decided to collect viral panel and CRP for SARS-Cov-2, in addition to starting empirical antibiotic therapy with ceftriaxone, azithromycin and oseltamivir. After reassessment, the ICU team decided to start chloroquine diphosphate on suspicion of COVID-19 (later confirmed).

Since then, other medications with the potential to prolong the QT interval were avoided and the patient was submitted to ECG daily - the QTc interval did not change in any routine ECG, as shown in Figure 4. On the second day of evolution, the patient presented increased troponin, without repercussions on ECG and ventricular function. On the fourth day of evolution, in the absence of clinical improvement, the antibiotic was switched to Piperacillin-Tazobactam. The next day, the patient developed acute respiratory failure, being submitted to orotracheal intubation and initiation of mechanical ventilation. After a few hours, she presented ventricular tachyarrhythmia with progression to cardiorespiratory arrest (CRA); electrocardiographic monitoring at the time of CRA demonstrated Torsades de Pointes
(Figure 4F). After cardiopulmonary resuscitation awith defibrillation, the perfusion rate returned. The ECG after the event showed only right bundle branch block, which disappeared on a routine ECG the following day. The transthoracic echocardiogram after CRA maintained preserved EF (60\%), without segmental deficit. After the event, the patient evolved with progressive clinical worsening due to multiple organ dysfunction, progressing to death on the 7th day of ICU stay.

In both cases presented, in addition to the combined use of chloroquine or hydroxychloroquine with azithromycin, patients were aging adults and were in the ICU in critical condition, which increases the chance of cardiovascular complications, both of ventricular dysfunction and ventricular arrhythmia. The first patient possibly had myocarditis (drop in ejection fraction, elevation of troponin and appearance of $Q$ wave in DI and AVL), evolving with bradycardia and cardiogenic shock. The prolongation of the QT interval results from the combination of chloroquine and azithromycin, facilitated by bradycardia and myocardial injury. Myocardial inflammation alters the membrane's action potential and the inflammatory mediators, including cytokines, and potentiate the blocking of hERG channels, predisposing to Torsades de Pointes.

In the second case, the patient had a sudden evolution to Torsades de Pointes, without documentation of the prolongation of the QT interval, which may have punctually preceded the arrhythmic event. The presence of atrial bigeminy eventually contributed to the dispersion of repolarization due to the irregularity of the
A - Admission to the ICU

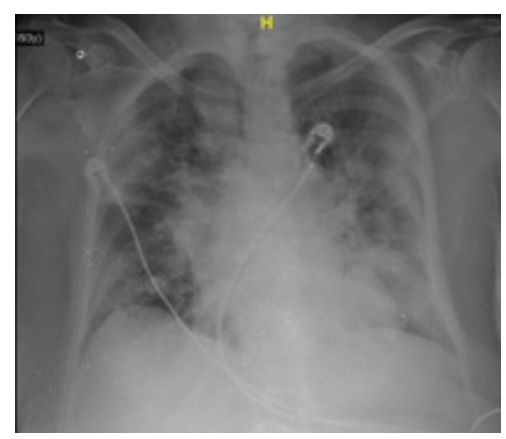

B - First day of admission

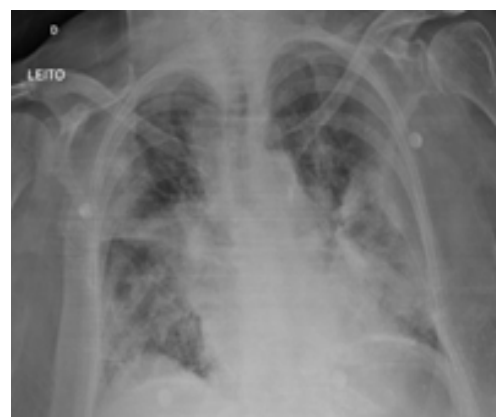



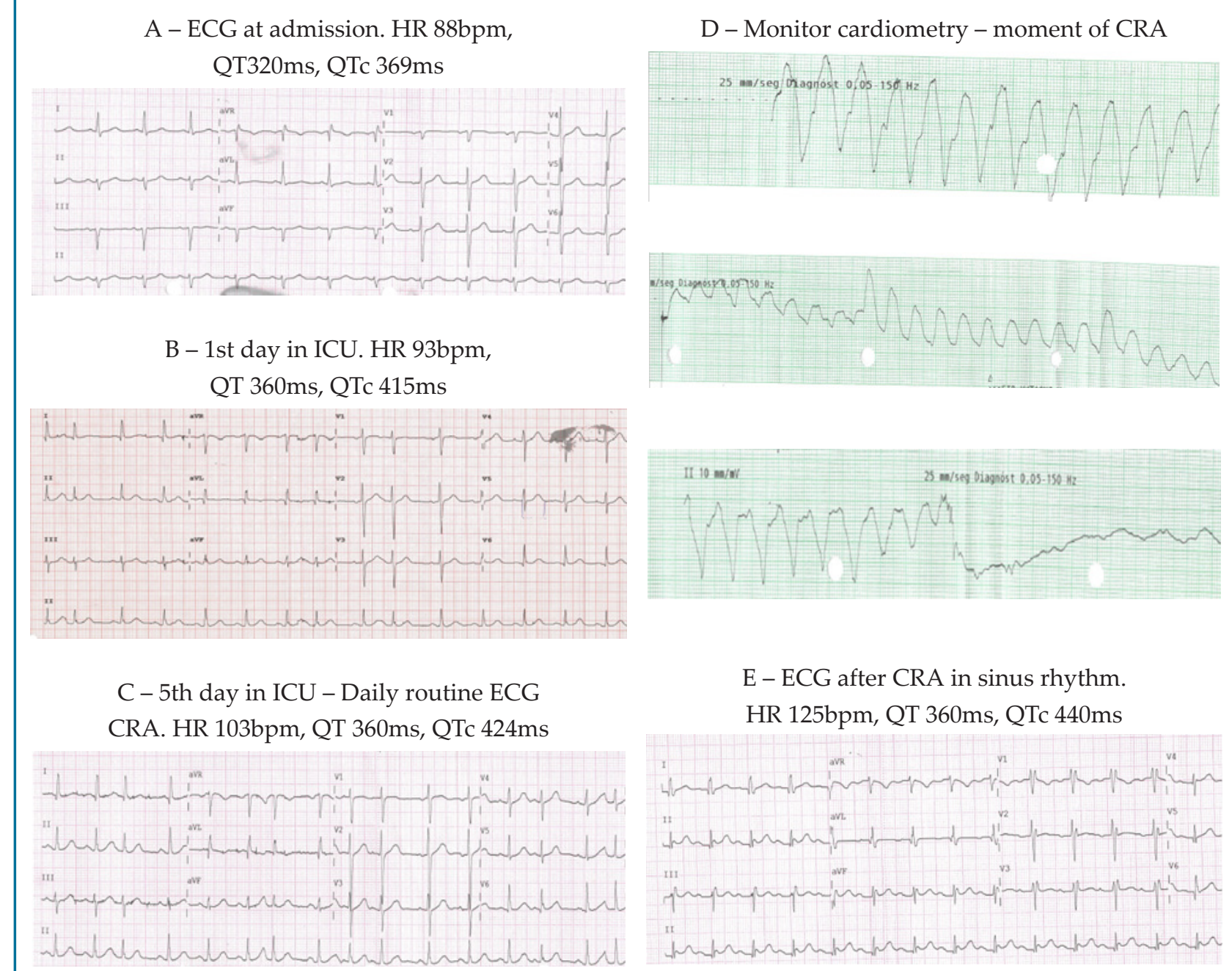

E - ECG after CRA in sinus rhythm. HR 125bpm, QT 360ms, QTc 440ms

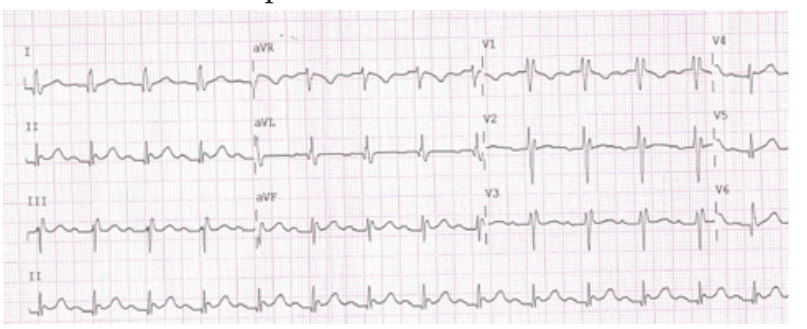

Figure 4 - Electrocardiographic evolution of Case 2. A - Admission, B - 1st day in the ICU, C - 5th day in the ICU - routine ECG on the day of CRA. Periods of atrial bigeminy, D - Monitor cardiometry - time of CRA, E - ECG after CRA in sinus rhythm, with new final conduction delay and first-degree AVB. ECG: electrocardiogram; HR: heart rate; CRA: cardiorespiratory arrest; ICU: intensive care unit.

RR interval. There were also a PR prolongation, a new final conduction delay, observed after CRA, in addition to early inferior repolarization, demonstrating the transmural dispersion in the plateau phase of the action potential, which may have potentiated arrhythmogenesis or be just an electrical phenomenon after CRA.

This will probably be the reality for most of the patients in whom these drugs will be administered for the treatment of severe COVID-19 infection - they will often be older adults, hemodynamically unstable using one or more vasopressors and on mechanical ventilation, with delicate handling of volume, often resulting in electrolyte disturbances.
If the option is to use these medications, it is necessary to use tools to identify the subgroup of individuals who, either by genetic predisposition (such as Long QT syndrome, with an incidence of 1:2000) or by the presence of multiple modifiable and non-modifiable factors for long acquired QT, have a greater risk for exposure to drugs that prolong QT. A risk score validated by Tisdale and colleagues to predict QT prolongation in hospitalized patients can be used for this purpose. ${ }^{23}$ The Tisdale score $\leq 6$ indicates low risk, 7-10 moderate risk, and $\geq 11$ high risk of prolonged QT related to drug use (Chart 1).

Therefore, the position at the moment is to employ the association of chloroquine / hydroxychloroquine with 
Table 2 - Clinical-laboratorial data Case 2.

\begin{tabular}{|c|c|c|c|c|c|c|c|}
\hline & Admission & D1 & D2 & D3 & D4 & D5 & D6 \\
\hline Hemoglobin (g/dL) & 11.5 & 11.2 & 10.1 & 10.5 & 13.3 & 10.3 & 10.4 \\
\hline Hematocrit (\%) & 34.1 & 331 & 30.1 & 32.6 & 39.4 & 29.2 & 30.9 \\
\hline Leukogram (cells/mm³) & 15990 & 9850 & 11800 & 10830 & 5290 & 9300 & 16980 \\
\hline Band cells (\%) & 0 & 0 & 0 & 0 & $3 \%$ & $3 \%$ & 0 \\
\hline Neutrophils (\%) & $54 \%$ & $80 \%$ & $87 \%$ & $70 \%$ & $74 \%$ & $77 \%$ & $84 \%$ \\
\hline $\begin{array}{l}\text { Lymphocytes (cells/ } \\
\mathrm{mm}^{3}-\% \text { ) }\end{array}$ & $1339-8.5 \%$ & $985-10 \%$ & $1298-11 \%$ & $1083-10 \%$ & $952-18 \%$ & $1023-11 \%$ & $2038-12 \%$ \\
\hline Platelets (cells/mm³) & 249.000 & 204.000 & 198.000 & 240.000 & 166.000 & 272.000 & 298.000 \\
\hline Urea (mg/dL) & 43 & 47 & 53 & 59 & 52 & 49 & 37 \\
\hline Creatinine (mg/dL) & 1.13 & 1.04 & 1.48 & 1.37 & 1.27 & 1.09 & 0.80 \\
\hline Sodium (mEq/L) & 129 & 131 & 134 & 139 & 137 & 139 & 135 \\
\hline Potassium (mEq/L) & 4.2 & 3.0 & 3.0 & 3.2 & 2.9 & 3.5 & 3.6 \\
\hline $\begin{array}{l}\text { Ionic calcium } \\
(\mathrm{mmol} / \mathrm{L})\end{array}$ & & 1.05 & 1.18 & 1.18 & 1.14 & 1.13 & 1.41 \\
\hline Phosphorus (mg/dL) & & & 4.1 & 3.8 & & 3.8 & \\
\hline Chlorine (mmol/L) & & & & & & 92 & \\
\hline Magnesium (mg/dL) & & 1.5 & 2.4 & 1.7 & 1.5 & 1.6 & 2.1 \\
\hline $\mathrm{BNP}(\mathrm{pg} / \mathrm{mL})$ & 1220 & & 916 & & 483 & 309 & 347 \\
\hline Troponin (mg/dL) & 55 & 224 & 109 & 40 & 35 & 25 & 490 \\
\hline Ferritin (ng/mL) & & 807 & 554 & 640 & 772 & 761 & 2653 \\
\hline D-dimer (ng/ml) & 2054 & & 1418 & & & & \\
\hline CRP (mg/dL) & & 8.16 & 15.27 & 17.76 & 16.27 & 13.92 & 1.27 \\
\hline Lactate (mg/dL) & 23 & 14 & 8 & 8 & 14 & 10 & 119 \\
\hline LDH (UI/l) & & 416 & 397 & 440 & 447 & 545 & 143 \\
\hline SWAB-COVID-19 & Positive & & & & & & \\
\hline
\end{tabular}

\section{Clinical Data}

\begin{tabular}{|c|c|c|c|}
\hline Use of vasopressors & & $x$ & $x$ \\
\hline Use of inotropic & & $x$ & $x$ \\
\hline Mechanical ventilation & & $x$ & $x$ \\
\hline $\begin{array}{l}\text { Ejection Fraction } \\
\text { (echocardiogram) }\end{array}$ & $61 \%$ & & $60 \%$ \\
\hline
\end{tabular}

BNP: brain natriuretic peptide; CRP: C-reactive protein; LDH: lactate dehydrogenase; QTc: corrected QT interval; LVEF: left ventricular ejection fraction. 
azithromycin with caution in patients with heart disease, and minimize the use of expendable drugs that prolong the QT interval directly (potassium channel blockers) or indirectly (by drug interaction). Electrocardiographic monitoring should be strengthened in patients who develop myocardial injury or cardiac arrhythmias.

\section{Author Contributions}

Conception and design of the research: Crivelari NC, Hajjar LA. Acquisition of data: Souza AC, Hajjar LA. Writing of the manuscript: Crivelari NC, Oliveira GQ, Park CHL, Riemma GC, Costa IBSS. Critical revision of the manuscript for intellectual content : Lacerda MVG, Oliveira GMM, Darrieux F, Sacilotto L, Hajjar LA.

\section{Ethics Approval and Consent to Participate}

This study was approved by the Ethics Committee of the Hospital Pró-Cardíaco under the protocol number CAAE: 3348.4020.8.0000.5533. All the procedures in this study were in accordance with the 1975 Helsinki Declaration, updated in 2013. Informed consent was obtained from all participants included in the study.

\section{Potential Conflict of Interest}

No potential conflict of interest relevant to this article was reported.

\section{References}

1. Dong E, Du H, Gardner L. An interactive web-based dashboard to track COVID-19 in real time. Lancet Infect Dis. 2020;20(5):533-4.

2. Ferner RE, Aronson JK. Chloroquine and hydroxychloroquine in covid-19. BMJ. 2020 Apr 8;369:m1432.

3. Wu Z, McGoogan JM. Characteristics of and Important lessons from the coronavirus disease 2019 (COVID-19) outbreak in China: summary of a report of 72314 cases from the Chinese Center for Disease Control and Prevention. JAMA. 2020 Feb 24. [Epub ahead of print].

4. Devaux CA, Rolain JM, Colson P, Raoult D. New insights on the antiviral effects of chloroquine against coronavirus: what to expect for COVID-19? Int J Antimicrob Agents. 2020;55(5):105938.

5. Akpovwa H. Chloroquine could be used for the treatment of filoviral infections and other viral infections that emerge or emerged from viruses requiring an acidic $\mathrm{pH}$ for infectivity. Cell Biochem Funct. 2016;34(4):191-6.

6. Livingston E, Bucher K. Coronavirus disease 2019 (COVID-19) in Italy. JAMA. 2020;323(14):1335.

7. Lenzer J. Covid-19: US gives emergency approval to hydroxychloroquine despite lack of evidence. BMJ. 2020 Apr 1;369:m1335.

8. Chorin E, Dai M, Shulman E, Wadhwani L, Cohen RB, Barbhaiya C, et al. The QT interval in patients with SARS-CoV-2 infection treated with hydroxychloroquine/azithromycin. medRxiv. 2020.04.02.20047050. [Preprint].

\section{Sources of Funding}

There were no external funding sources for this study.

\section{Study Association}

This study is not associated with any thesis or dissertation work.

\begin{tabular}{ll}
\multicolumn{1}{c}{ Tisdale risk score } & \\
\hline \multicolumn{1}{c}{ Risk factors } & Points \\
\hline \multicolumn{1}{c}{ Age $\geq 68$ years } & 1 \\
Female sex & 1 \\
Loop diuretic & 1 \\
Serum K+ $\leq 3.5$ mEq / L & 2 \\
ECG admission with QTc $\geq 450 m s$ & 2 \\
Acute Myocardial Infarction) & 2 \\
$\geq 2$ drugs that prolong QTc & 3 \\
Sepsis & 3 \\
Cardiac insufficiency & 21 \\
A drug that prolongs QTc & 3 \\
Maximum risk score & 3 \\
\hline hospitalized patients. & \\
\hline
\end{tabular}

9. Madrid PB, Panchal RG, Warren TK, Shurtleff AC, Endsley AN, Green $\mathrm{CE}$, et al. Evaluation of Ebola virus inhibitors for drug repurposing. ACS Infect Dis. 2015;1(7):317-26.

10. Bosseboeuf E, Aubry M, Nhan T, Pina JJ, Rolain JM, Raoult D, et al. Azithromycin inhibits the replication of Zika virus. J Antivir Antiretrovir. 2018;10(1):6-11.

11. Bacharier LB, Guilbert TW, Mauger DT, Boehmer S, Beigelman A, Fitzpatrick AM, et al. Early administration of azithromycin and prevention of severe lower respiratory tract illnesses in preschool children with a history of such illnesses: a randomized clinical trial. JAMA. 2015;314(19):2034-44.

12. Cortegiani A, Ingoglia G, Ippolito M, Giarratano A, Einav S. A systematic review on the efficacy and safety of chloroquine for the treatment of COVID-19. J Crit Care. 2020 Jun;57:279-283.

13. Brasil. Ministério da Saúde. NOTA INFORMATIVA № 6/2020-DAF/ SCTIE/MS. Atualiza informações sobre o uso da cloroquina como terapia adjuvante no tratamento de formas graves do COVID-19, ficando revogada a Nota Informativa $\mathrm{n}^{\mathrm{o}}$ 5/2020-DAF/SCTIE/MS, datada de 27 de março de 2020 [nota na internet]. [acesso em 21 mar 2020]. Disponível em: https://www.mpma.mp.br/arquivos/CAOPSAUDE/MS---0014223901--Nota-Informativa-n---6-2020-DAF-SCTIE-MS.pdf.

14. Colson P, Rolain JM, Lagier JC, Brouqui P, Raoult D. Chloroquine and hydroxychloroquine as available weapons to fight COVID-19. Int J Antimicrob Agents. 2020;55(4):105932. 
15. Gautret P, Lagier JC, Parola P, Hoang VT, Meddeb L, Mailhe M, et al. Hydroxychloroquine and azithromycin as a treatment of COVID-19: results of an open-label non-randomized clinical trial. Int J Antimicr Agents. 2020 March 20. [Epub ahead of print].

16. Stas P, Faes D, Noyens P. Conduction disorder and QT prolongation secondary to long- term treatment with chloroquine. Int J Cardiol. 2008;127(2):e80-2.

17. Giudicessi JR, Ackerman MJ. Azithromycin and risk of sudden cardiac death: guilty as charged or falsely accused? Cleve Clin J Med. 2013;80(9):539-44.

18. Chen CY, Wang FL, Lin CC. Chronic hydroxychloroquine use associated with QT prolongation and refractory ventricular arrhythmia. Clin Toxicol (Phila). 2006;44(2):173-5.

19. Arellano-Rodrigo E, Garcia A, Mont L, Roqué M. Torsade de pointes and cardiorespiratory arrest induced by azithromycin in a patient with congenital long QT syndrome. Med Clin (Barc). 2001;117(3):118-9.
20. Shi S, Qin M, Shen B, Cai Y, Liu T, Yang F, et al. Association of cardiac injury with mortality in hospitalized patients with COVID-19 in Wuhan, China. JAMA Cardiol. 2020 Mar 25;e200950. [Epub ahead of print].

21. Chico RM, Chandramohan D. Azithromycin plus chloroquine: combination therapy for protection against malaria and sexually transmitted infections in pregnancy. Expert Opin Drug Metab Toxicol. 2011;7(9):1153-67.

22. Rock EP, Finkle J, Fingert HJ, Booth BP, Garnett CE, Grant S, et al Assessing proarrhythmic potential of drugs when optimal studies are infeasible. Am Heart J. 2009;157(5):827-36.

23. Tisdale JE, Jayes HA, Kingery JR, Mourad NA, Trujillo TN, Overholser $\mathrm{BR}$, et al. Development and validation of a risk score to predict QT interval prolongation in hospitalized patients. Circ Cardiovasc Qual Outcomes. 2013;6(4):479-87. 